\title{
Interactive comment on "Evaluation of coastal Antarctic precipitation in MAR3.9 regional and LMDz6 global atmospheric model with ground-based radar observations" by Florentin Lemonnier et al.
}

\section{Charles Amory}

charles.amory@uliege.be

Received and published: 6 October 2020

Dear authors,

As the main developers of the regional climate model MAR, we would like to raise strong reservations on the work proposed with MAR in this paper because of inconsistency of the methodology followed to analyze the sensitivity to horizontal grid size. Our comments also include recommendations for the description of the model, very diverging in its current state from what we do try to follow in our respective publications. 
Although LMDz has been mostly designed for representing the atmospheric dynamics over large integration domains over which the model is much more free to evolve, the evaluation of the model ability to represent over small domains observed precipitation profiles at DDU and the sensitivity analysis to resolution and dissipation are very interesting. Regarding MAR, the description of the model must be more thorough, and simulations at $25 \mathrm{~km}$ resolution over the SMALL (10x10 pixels) and BIG (40x40 pixels) domains cannot be mentioned due to the too weak number of pixels that prevents MAR to simulate its own circulation, making the results meaningless. We strongly recommend to discard these results from the paper and to focus more on the LMDz simulation and possibly on the $5 \mathrm{~km}$ simulation with MAR to strengthen the quality and the scientific robustness of the paper. Our comments are reported below.

\section{Cécile Agosta, Xavier Fettweis, Christoph Kittel and Charles Amory}

1. Please double check which version of MAR was actually used in the study since only MAR4 is able to go down $15 \mathrm{~cm}$ in vertical resolution. Moreover, any version of MAR3 does not enable simulation on a domain smaller than $60 \times 60$ grid points, as done in this study. Any currently published study with MAR3 below version 3.11 does not include a blowing-snow scheme, which has only been evaluated and made functional recently. If the study has been carried out with MAR4, it should appear clearly in the text (and the title) without ambiguity to keep consistency from one evaluation exercise to another and prevent confusion between the actual capabilities of different model versions. In that case, referring also to the performance of MAR3 (stable version) to support the use of MAR4 (currently in development) must be avoided given the too large differences between the two models. If the version is truly MAR3.9, this must be stated as is in the text but the description of the model set-up needs to be adapted to fit with Kittel et al. (2018) and Agosta et al. (2019). Please adapt the code and data availability section accordingly since MAR4 has not been made publicly available yet.

2. P3 L24: The atmospheric radiative transfer in MAR3/MAR4 is adapted from Morcette (2002).

Printer-friendly version

Discussion paper
Interactive comment 
3. P4 L20-24 : Avoid wording "accurately" when it's not supported by good agreement with observations. MAR3 has only been "officially" extensively evaluated so far against near-surface meteorological observations, and against few atmospheric profiles collected in stable environments very different from your measurement location for which local turbulence schemes (as implemented in MAR) are known to misrepresent the well-mixed character of neutral $A B L$, and thus $U, T, R H$ and ultimately sublimation profiles. From this perspective, we suggest to reformulate with "MAR includes a detailed representation of the ABL" and refer to some relevant publications. Similarly, the blowing-snow scheme is not activated nor evaluated in Agosta et al. (2019), neither the interactions with katabatic winds. Please reformulate this as well. Sublimation of blowing snow may influence the relative humidity and then the sublimation potential of precipitation within the lowest part of the atmospheric boundary layer (Grazioli et al., 2017b), which falls well within the scope of the study. Finally, note that the very small additional computational cost required for activation of the blowing-scheme cannot be reasonably used as a justification for disabling it. If you're using MARv3.9, use the same justification than in Kittel et al. (2018) or Agosta et al. (2019).

4. P4 L25: + surface pressure at the model lateral boundaries + SST and SIC at the surface of the ocean.

5. P4 L26: "optimal" may be too emphatic. There is no comparison nor sensitivity analysis that would support this configuration is more advisable than other ones likely to lead to similar results.

6. P4 L28-29: The fine discretization close to the surface is not a sufficient argument to state that MAR is accurate in the absence of quantitative comparison with observations. Please change wording.

7. P4 L30: How has the duration of 4 months been chosen for the spin-up of MAR? It seems that the authors refer here to the spin-up needed for the atmosphere to reach equilibrium, not for the snowpack (which would require a longer spin-up). Is there any

Printer-friendly version

Discussion paper 
reason justifying why MAR would require a shorter spin-up than LMDZ?

8. P6 Section $2.4+P 8$ section 3.1: Contrary to $L M D z, M A R$ is only forced at its lateral boundaries by surface pressure, temperature, specific humidity, and wind speed. The formation of clouds and resulting precipitation can therefore only be achieved after a considerable distance away from the boundaries, and so it is for the fine-scale circulation. For any simulation, the area of interest must be located at least 20 pixels away from each of the 4 lateral boundaries. Running a RCM over a domain that actually corresponds to the relaxation zone (SMALL $25 \mathrm{~km}, 10 \times 10$ pixels) is meaningless. This is more or less an interpolation of the ERA-Interim large-scale fields on the model grid without any cloud nor precipitation, and does not constitute any model result. Similarly the size of the BIG domain is also prohibitive for the run at $25 \mathrm{~km}$ resolution because MAR is still too influenced by the large-scale forcing at the center of its domain. Without enlarging the domain at $25 \mathrm{~km}$, these results (and every related comment) could not be used for a reasonable scientific demonstration and must be removed from the study. Note that using MARv3, Franco et al., (2012) showed that precipitation remains globally unaffected by changes in resolution and even obtained inverse results from that presented here (the higher the resolution, the larger the precipitation rates).

9. Fig. 2 : Indicate DDU on the MAR continental pixel from which the modelled vertical profile has been extracted.

10. P6 L10-12: The reference to Franco et al. (2012) is inappropriate here since the resolution they used reflects the compromise between computational time and model accuracy due to the large number of simulations, but not model capabilities. Please remove.

11. P8 L25-26: As explained above, this is a matter of scientific meaning and not model capabilities of former MAR versions or "not optimal" configurations. Please remove.

12. P8 L9 : Consider linking this bias not to MAR but to the version of the model used in this study since biases can change depending on the version. This is why it is of first

Printer-friendly version

Discussion paper
Interactive comment 
importance to specify the version used.

Agosta, C., Amory, C., Kittel, C., Orsi, A., Favier, V., Gallée, H., van den Broeke, M. R., Lenaerts, J., vanWessem, J. M., van de Berg,W. J., et al.: Estimation of the Antarctic surface mass balance using the regional climate model MAR (1979-2015) and identification of dominant processes, Cryosphere, 13, 281-296, 2019.

Franco, B., Fettweis, X., Lang, C., and Erpicum, M.: Impact of spatial resolution on the modelling of the Greenland ice sheet surface mass balance between 1990-2010, using the regional climate model MAR, The Cryosphere, 6, 695-711, https://doi.org/10.5194/tc-6-695-2012, 2012.

Grazioli, J., Madeleine, J.-B., Gallée, H., Forbes, R. M., Genthon, C., Krinner, G., and Berne, A.: Katabatic winds diminish precipitation contribution to the Antarctic ice mass balance, Proceedings of the National Academy of Sciences, 114, 10 858-10 863, 2017b.

Kittel, C., Amory, C., Agosta, C., Delhasse, A., Doutreloup, S., Huot, P.-V., Wyard, C., Fichefet, T., and Fettweis, X.: Sensitivity of the current Antarctic surface mass balance to sea surface conditions using MAR, The Cryosphere, 12, 3827-3839, https://doi.org/10.5194/tc-12-3827-2018, 2018.

Morcrette, J.-J.: Assessment of the ECMWF model cloudiness and surface radiation fields at the ARM SGP site, Mon.Weather Rev., 130, 257-277, https://doi.org/10.1175/1520- 0493(2002)130<0257:AOTEMC>2.0.CO;2, 2002.

Interactive comment on The Cryosphere Discuss., https://doi.org/10.5194/tc-2020-167, 2020. 